\title{
Association between obesity and metabolic co-morbidities among children and adolescents in South Korea based on national data
}

Hyunjung Lim ${ }^{1,2}$, Hong Xue $\mathrm{e}^{3,4}$ and Youfa Wang ${ }^{3,4^{*}}$

\begin{abstract}
Background: Childhood obesity has become a serious public health threat worldwide due to its many short- and long-term adverse health effects. We assessed the association between weight status and metabolic co-morbidities among South Korean children using nationally representative data.

Methods: Data from the 2007-2008 Korea National Health and Nutrition Examination Surveys for 1,526 children aged 10-19 years were used. Logistic regression models were fit to examine the association between weight status [overweight, $85^{\text {th }}$ percentile $\leq \mathrm{BMl}<95^{\text {th }}$ percentile; obese, $\mathrm{BMI} \geq 95^{\text {th }}$ percentile; and central obesity, waist circumference $\geq 90^{\text {th }}$ percentile, based on 2007 Korean National Growth Charts] and metabolic outcomes.

Results: More obese children had metabolic co-morbidities than normal-weight children $(P<0.05)$. Boys had higher means BMI than girls, WC, and BP, while girls had higher means of total blood cholesterol and HDL-cholesterol $(P<0.05)$. Attributable risk of metabolic syndrome was high due to overweight and obesity: $91.1 \%$ for central obesity and 29.6\% for high TG. Obese children had increased risk of having high BP (adjusted odds ratio (OR): 1.90; 95\% Cl: 1.05-3.45), dyslipidemia (OR: 6.21; 95\% Cl: 3.59-10.75), high TG (OR: 6.87; 95\% Cl: 4.05-11.64), low HDL (OR: 4.46; 95\% Cl: 2.23-8.89), and $\geq 2$ co-morbidities (OR: $26.97 ; 95 \%$ Cl: 14.95-48.65) compared to normal-weight subjects, while the associations between weight status and metabolic outcomes were stronger in boys.
\end{abstract}

Conclusions: Obesity was strongly associated with metabolic co-morbidities in South Korean children.

Keywords: Child, Adolescents, Body mass index, Obesity, Metabolic co-morbidity, Metabolic syndrome, South Korean, Waist

\section{Background}

Worldwide prevalence of childhood obesity has increased remarkably over the past three decades [1]. Overweight or obese children are at a high risk for developing long-term chronic conditions, including high blood pressure (BP), elevated blood glucose, dyslipidemia, and metabolic syndrome (MetS) [2,3], which are metabolic co-morbidities of obesity.

\footnotetext{
* Correspondence: youfawan@buffalo.edu

${ }^{3}$ Johns Hopkins Global Center on Childhood Obesity, Department of International Health, Johns Hopkins Bloomberg School of Public Health, Baltimore, MD, USA

${ }^{4}$ Department of Epidemiology and Environmental Health, School of Public Health and Health Professions, University at Buffalo, State University of New York, Buffalo, NY, USA

Full list of author information is available at the end of the article
}

As South Korea became industrialized, energy intake and sedentary activities (e.g., screen time) have increased. Based on the 2011 Korea national health statistics, among Korean adults aged 30 and older, the prevalence of obesity $\left(B M I \geq 30 \mathrm{~kg} / \mathrm{m}^{2}\right)$, hypertension, diabetes, hypercholesterolemia, and hypertriglyceridemia is $34.2 \%, 30.8 \%$, $10.5 \%, 14.5 \%$, and $16.5 \%$, respectively. The rates have been increasing [4].

The prevalence of childhood obesity doubled from 5.4\% in 1998 to $10.8 \%$ in 2008 in South Korea, although it is still low compared to Western countries [5,6]. Moreover, among Korean adolescents body weight status misperception (51.6\% of boys; $48.6 \%$ of girls) is common based on the 2009 nationally representative data. It is strongly associated with poor eating behaviors, and stress or depressed moods [7]. However, little is known about the association

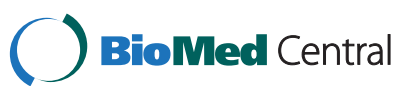


between weight status and metabolic co-morbidities among children in South Korea [6]; previous related studies were mainly based on data that is 10 years old, and the gender-age specific association between metabolic comorbidities and weight status has not been sufficiently examined.

To fill this gap, this study assessed the association between weight status and metabolic co-morbidities by gender among children aged 10-19 years in South Korea using nationally representative data. We also investigated the aspect of metabolic co-morbidities in overweight/obese children. The findings may help guide future screening of high-risk groups and guide related interventions.

\section{Methods}

\section{Study population and database}

We used data from the fourth Korea National Health and Nutrition Examination Surveys (KNHANES IV, 2007-08). KNHANES is a series of population-based, cross-sectional surveys that selects a representative group by using a stratified, multistage sampling design according to geographic area, age, and gender. Since 2007, the KNHANES has become a year-round investigation with rolling survey sampling. Stratification was conducted based on the country's 29 areas, including 11 metropolitan cities and provinces, the administrative unit, and the dwelling type. The instruments included a health interview survey, a health examination survey, and a nutrition survey. The health interview survey collected information regarding socio-demographic characteristics. Anthropometry, BP measures and laboratory tests of the subjects were obtained by direct health examination in a mobile examination center. Detailed descriptions of the study design and data collection have been published [8]. The KNHANES IV was approved by the Korea Centers for Disease Control \& Prevention Institutional Review Board.

Blood sample laboratory tests among children under 10 years of age were not available. We focused on a sample of 3,618 children (1,658 boys and 1,510 girls) aged 10-19 years with complete demographic data. After excluding 645 subjects without body mass index (BMI) measures and 1,447 subjects without metabolic co-morbidities parameters such as waist circumference (WC), BP, glucose, triglyceride (TG) and total cholesterol (TC), and high-density lipoprotein cholesterol (HDL-C), we had a final sample of 1,526 subjects (821 boys and 705 girls) for our analyses.

\section{Data collection and key measurements Anthropometric measures}

Standing height (seca 225, SECA, Germany) and weight (GL-6000-20, CASKOREA Co., Ltd., Korea) were obtained using standardized techniques and equipment. WC was measured at the midpoint between the subcostal bottom and the top of the iliac crest using a fiberglass tape (seca 200, SECA, Germany).

\section{Blood pressure (BP)}

Three BP determinations were obtained by standard methods with the subject in a sitting position using a mercury sphygmomanometer. After rest while seated, $\mathrm{BP}$ was measured 3 times at 30 second intervals. The average of the second and third measurements was used in our analysis.

\section{Laboratory tests}

All blood specimen collection and processing instructions are described in the KNHANES Laboratory/Medical Technologists Procedures Manual [9]. Blood samples were collected in the morning after fasting for at least 8 hours. Fasting blood glucose was analyzed using a reaction between glucose and ATP catalyzed by the enzyme hexokinase. The concentrations of TG, TC, and HDL-C were also measured using an enzymatic method. Fasting blood glucose, TG, TC, and HDL-C levels were measured using an automated hematology analyzer (ADVIA 1650, Siemens, USA) in a central, certified laboratory. The low-density lipoprotein cholesterol (LDL-C) concentration was estimated by the Friedewald formula (LDL cholesterol $=$ total cholesterol-HDL cholesterol-triglycerides/5) [10].

\section{Definition of weight status}

To define weight status, BMI was calculated based on measured weight and height $(\mathrm{BMI}=$ weight $(\mathrm{kg}) /$ squared height $\left(\mathrm{m}^{2}\right)$ ). We used the 2007 Korean National Growth Charts [11]. Subjects were classified as a) normal weight, $5^{\text {th }}$ percentile $\leq \mathrm{BMI}<85^{\text {th }}$ percentile; b) overweight, $85^{\text {th }}$ percentile $\leq \mathrm{BMI}<95^{\text {th }}$ percentile; c) obese, $\mathrm{BMI} \geq 95^{\text {th }}$ percentile [11].

Central obesity is defined as $\mathrm{WC} \geq 90$ th percentile for age and gender based on 2007 Korea Growth Charts [11] in children aged 10 to $<16$ yrs., and $\geq 90 \mathrm{~cm}$ for men and $\geq 85 \mathrm{~cm}$ for women as the Korean-specific criterion [12] in adolescents aged $\geq 16$ yrs.

\section{Definition of metabolic co-morbidities}

The definition of metabolic co-morbidities for our study was as follows:

1) Prehypertension and hypertension [13]: systolic $\mathrm{BP} /$ diastolic $\mathrm{BP} \geq 90$ th percentile for age, gender, and height based on 2007 Korea Growth Chart [11]

2) High glucose [14]: fasting blood glucose $\geq$ $100 \mathrm{mg} / \mathrm{dL}[14]$

3) Dyslipidemia [15]: high TG, high TC, high LDL-C, or low HDL-C [15]

i) High TG: Triglyceride $>150 \mathrm{mg} / \mathrm{dL}$ 
ii) High TC: Total cholesterol $>200 \mathrm{mg} / \mathrm{dL}$

iii) $\mathrm{LDL}$-cholesterol $>130 \mathrm{mg} / \mathrm{dL}$

iv) HDL-cholesterol $<35 \mathrm{mg} / \mathrm{dL}$

4) Metabolic syndrome: Having central obesity plus $\geq 2$ of the following criteria based on the 2007 pediatric International Diabetes Federation (IDF) definition [16]

i) elevated BP: systolic $\mathrm{BP} \geq 130$ or diastolic $\mathrm{BP} \geq$ $85 \mathrm{~mm} \mathrm{Hg}$, or treatment of previously diagnosed hypertension

ii) elevated fasting plasma glucose: $\geq 100 \mathrm{mg} / \mathrm{dL}$ $(5.6 \mathrm{mmol} / \mathrm{L})$, or previously diagnosed type 2 diabetes

iii) elevated TG level: $\geq 150 \mathrm{mg} / \mathrm{dL}(1.7 \mathrm{mmol} / \mathrm{L})$, or specific treatment for this lipid abnormality

iv) reduced HDL cholesterol: $<40 \mathrm{mg} / \mathrm{dL}$

$(1.03 \mathrm{mmol} / \mathrm{L})$ in children aged $10-16 \mathrm{yrs}$ and boys aged $16-19 \mathrm{yrs}$, and $<50 \mathrm{mg} / \mathrm{dL}$

$(1.29 \mathrm{mmol} / \mathrm{L})$ in girls aged $16-19 \mathrm{yrs}$, or specific treatment for this lipid abnormality

\section{Statistical analysis}

Our key outcome variables were the presence of metabolic co-morbidities (e.g., central obesity, high BP, high glucose, dyslipidemia, metabolic syndrome). The key exposure categorical variable was weight status classified as normal weight, overweight, obesity, and central obesity. Analysis stratified by age and gender was conducted. The complex sample design was taken into account in the analysis using STATA release 11.0 survey-related commands, to give nationally representative estimates and correct estimates of the related variances.

First, we examined the gender and weight status differences in metabolic co-morbidities. Between-group differences in means were tested using $t$ test and ANOVA, and the prevalence differences of metabolic co-morbidities were tested using $\chi^{2}$ tests. We also tested the trends across weight status (normal weight, overweight, obesity) and calculated population attributable risk (PAR, \%) [17].

Then, to examine the association between weight status and metabolic co-morbidities (outcome variables), we fitted logistic regression models, controlling for socioeconomic and other environmental factors, including urban-rural residence region, household income as the quartiles of average household monthly income, and menarche status (for girls).

\section{Results}

Prevalence of metabolic co-morbidities by gender and weight status

Most participants (81.6\%) lived in urban areas. Age distribution, urban-rural residence region, and household income did not differ significantly across the three categories of weight status. Table 1 shows the distribution of metabolic outcomes by gender and weight status. Boys suffered worse metabolic outcomes in terms of high WC level and elevated BP level compared to girls, whereas girls had higher mean TC and HDL-C levels $(\mathrm{P}<0.05)$ than boys. Obese children had significantly higher means for most metabolic outcomes (e.g., BMI, WC, BP, TG, TC, LDL-C, atherogenic index = defined as $\log (\mathrm{TG} / \mathrm{HDL}-\mathrm{C})$, waist-to-height ratio); while, mean HDL-C level was the highest among normal-weight children (all $\mathrm{P}<0.05$ ).

Regarding prevalence of metabolic abnormalities, obese children had a high prevalence of MetS, central obesity, high BP, dyslipidemia and all individual blood lipid profiles $(\mathrm{P}<0.05)$, except for the prevalence of high glucose $(P>0.05)$. In addition, the proportion of children with 2 or more metabolic co-morbidities is higher among overweight and obese children than their normal weight counterparts $(5.7 \%$ in normal weight vs. $17.5 \%$ in overweight vs. $60.3 \%$ in obese children, $\mathrm{P}<0.05$ ).

\section{Attributable risk of metabolic comorbidities to overweight or obesity by gender}

Overall, the risk of metabolic co-morbidities attributable to overweight or obesity was high for MetS (100.0\%), central obesity (91.1\%), and $\geq 2$ metabolic co-morbidities (47.3\%); modest for high TG (29.6\%), dyslipidemia (20.2\%), and low HDL (17.7\%); and relatively low for high BP (7.7\%) and high glucose (10.0\%) (Figure 1). Boys had high attributable risk rates of metabolic comorbidities compared to girls, except for the attributable risk due to high glucose (6.1\% in boys vs. $14.4 \%$ in girls).

\section{Association between weight status and metabolic co- morbidities by gender}

Table 2 shows the associations between weight status and metabolic co-morbidities. After adjusting for age, gender, income, urban-rural residence, and menarche status (only for girls), the estimates showed that: 1) obese children were more likely to have high BP (OR, 1.90; 95\% CI, 1.053.45), dyslipidemia (OR, 6.21; 95\% CI, 3.59-10.75), high TG (OR, 6.87; 95\% CI, 4.05-11.64), high TC (OR, 2.80; 95\% CI, 1.10-5.62), high LDL (OR, 3.81; 95\% CI, 1.877.80), low HDL (OR, 4.46; 95\% CI, 2.23-8.89), and $\geq 2$ co-morbidities (OR: 26.97; 95\% CI: 14.95-48.65) than normal-weight subjects $(\mathrm{P}<0.05)$; and 2$)$ centrally obese children had higher risks of having dyslipidemia (OR, 3.87; 95\% CI, 2.45-6.13), other blood lipid profiles (OR, 2.04-4.12, $\mathrm{P}<0.05$ ), and $\geq 2$ co-morbidities (OR: 19.90; 95\% CI: 12.09-32.76) than children who were not centrally obese.

Our results suggested strong associations between weight status and metabolic outcomes in boys, in particular. In contrast, co-morbidities such as high BP, high TC, high LDL, and low HDL were not significantly associated with weight status in girls. However, centrally 
Table 1 Means and proportions of metabolic outcomes by gender and weight status among children aged 10-19-y-old in South Korea: KNHANES 2007-2008 ${ }^{1}$

\begin{tabular}{|c|c|c|c|c|c|c|c|c|c|c|c|c|}
\hline & \multicolumn{6}{|c|}{ By gender } & \multicolumn{6}{|c|}{ By weight status ${ }^{2,3,4}$} \\
\hline & \multirow{2}{*}{\multicolumn{2}{|c|}{$\begin{array}{c}\text { Total } \\
(n=1526)\end{array}$}} & \multirow{2}{*}{\multicolumn{2}{|c|}{$\begin{array}{c}\text { Boys } \\
(n=821)\end{array}$}} & \multirow{2}{*}{\multicolumn{2}{|c|}{$\begin{array}{c}\text { Girls } \\
(n=705)\end{array}$}} & \multirow{2}{*}{\multicolumn{2}{|c|}{$\begin{array}{c}\text { Normal weight } \\
(n=1147)\end{array}$}} & \multirow{2}{*}{\multicolumn{2}{|c|}{$\begin{array}{c}\text { Overweight } \\
(n=194)\end{array}$}} & \multirow{2}{*}{\multicolumn{2}{|c|}{$\begin{array}{c}\text { Obese } \\
(n=90)\end{array}$}} \\
\hline & & & & & & & & & & & & \\
\hline & Mean & $\overline{\mathrm{SE}}$ & Mean & SE & Mean & $\mathrm{SE}$ & Mean & SE & Mean & SE & Mean & SE \\
\hline \multicolumn{13}{|l|}{ Anthropometry } \\
\hline Body mass index $\left(\mathrm{kg} / \mathrm{m}^{2}\right)$ & 20.5 & 0.1 & 21.0 & 0.2 & 20.0 & $0.1^{5}$ & 19.6 & $0.1^{c}$ & 24.7 & $0.1^{\mathrm{b}}$ & 28.9 & $0.4^{\mathrm{a}}$ \\
\hline Waist circumference $(\mathrm{cm})$ & 70.0 & 0.3 & 72.2 & 0.5 & 67.3 & $0.4^{5}$ & 67.4 & $0.3^{c}$ & 80.3 & $0.6^{\mathrm{b}}$ & 90.3 & $1.5^{\mathrm{a}}$ \\
\hline Systolic blood pressure (mmHg) & 104.0 & 0.4 & 106.5 & 0.5 & 101.0 & $0.4^{5}$ & 102.9 & $0.4^{c}$ & 108.0 & $0.9^{b}$ & 112.9 & $1.5^{\mathrm{a}}$ \\
\hline Diastolic blood pressure $(\mathrm{mmHg})$ & 65.4 & 0.4 & 66.7 & 0.5 & 64.0 & $0.5^{5}$ & 65.0 & $0.4^{\mathrm{b}}$ & 67.6 & $0.9^{\mathrm{a}}$ & 67.6 & $1.5^{\mathrm{a}}$ \\
\hline \multicolumn{13}{|l|}{ Laboratory tests } \\
\hline Triglycerides (mg/dL) & 90.8 & 1.9 & 89.6 & 2.7 & 92.1 & 2.4 & 82.9 & $1.7^{\mathrm{C}}$ & 119.3 & $8.4^{\mathrm{b}}$ & 142.0 & $10.6^{\mathrm{a}}$ \\
\hline Total cholesterol (mg/dL) & 157.8 & 0.9 & 155.5 & 1.2 & 160.5 & $1.1^{5}$ & 155.6 & $1.0^{c}$ & 167.0 & $2.2^{\mathrm{b}}$ & 175.9 & $3.0^{\mathrm{a}}$ \\
\hline LDL-cholesterol (mg/dL) & 89.9 & 0.8 & 88.8 & 1.1 & 91.2 & 1.1 & 88.5 & $0.9^{c}$ & 96.2 & $2.1^{\mathrm{b}}$ & 105.2 & $3.2^{\mathrm{a}}$ \\
\hline HDL-cholesterol (mg/dL) & 49.7 & 0.5 & 48.8 & 0.6 & 50.8 & $0.6^{5}$ & 50.6 & $0.6^{\mathrm{a}}$ & 47.0 & $0.9^{b}$ & 42.2 & $1.4^{c}$ \\
\hline Fasting blood glucose (mg/dL) & 89.3 & 0.4 & 89.6 & 0.5 & 88.8 & 0.4 & 89.0 & $0.3^{b}$ & 91.6 & $1.3^{\mathrm{a}}$ & 89.8 & $1.0^{\mathrm{ab}}$ \\
\hline Atherogenic index ${ }^{7}$ & -0.3 & 0.0 & -0.3 & 0.0 & -0.3 & 0.0 & -0.4 & $0.0^{c}$ & -0.1 & $0.1^{\mathrm{b}}$ & 0.3 & $0.2^{\mathrm{a}}$ \\
\hline \multirow[t]{2}{*}{ Waist-to-height ratio } & 0.4 & 0.0 & 0.4 & 0.0 & 0.4 & $0.0^{5}$ & 0.4 & $0.0^{c}$ & 0.5 & $0.0^{\mathrm{b}}$ & 0.6 & $0.0^{\mathrm{a}}$ \\
\hline & \multicolumn{2}{|l|}{$\%$} & \multicolumn{2}{|c|}{$\%$} & \multicolumn{2}{|l|}{$\%$} & \multicolumn{2}{|c|}{$\%$} & \multicolumn{2}{|c|}{$\%$} & \multicolumn{2}{|c|}{$\%$} \\
\hline \multicolumn{13}{|l|}{ Obesity status } \\
\hline Central obesity, $\%^{8}$ & \multicolumn{2}{|l|}{8.1} & \multicolumn{2}{|c|}{8.9} & \multicolumn{2}{|c|}{7.2} & \multicolumn{2}{|c|}{0.9} & \multicolumn{2}{|c|}{20.8} & \multicolumn{2}{|c|}{$77.6^{6}$} \\
\hline Overweight and obesity, \%² & \multicolumn{2}{|c|}{19.0} & 21. & & 16.7 & & & & & & & \\
\hline Cadiometabolic risk factors & & & & & & & & & & & & \\
\hline Metabolic syndrome, $\%{ }^{6}$ & 1.9 & & 2.4 & & 1.3 & & & & 3 & & & \\
\hline High blood pressure, $\%^{7}$ & 17.5 & & 20. & & 14.7 & & & & 22 & & & \\
\hline High glucose, $\%^{8}$ & 6.7 & & 7.1 & & 6.3 & & & & 8 & & & \\
\hline Dyslipidemia, $\%{ }^{9}$ & 21.2 & & 21. & & 20.4 & & & & 38 & & & \\
\hline High triglycerides, $\%^{9}$ & 10.2 & & 10. & & 10.4 & & & & 21 & & & \\
\hline High total cholesterol, $\%{ }^{9}$ & 6.2 & & 5.6 & & 6.8 & & & & 10 & & & \\
\hline High LDL-cholesterol, $\%{ }^{9}$ & 5.6 & & 5.2 & & 6.0 & & & & 7 & & & \\
\hline Low HDL-cholesterol, \% ${ }^{9}$ & 7.9 & & 9.2 & & 6.3 & & & & 12 & & & \\
\hline No. of metabolic comorbidities, & & & & & & & & & & & & \\
\hline 0 & 61.4 & & 60.8 & & 62.2 & & & & 36 & & & \\
\hline 1 & 28.4 & & 28. & & 27.9 & & & & 46 & & & \\
\hline$\geq 2$ & 10.2 & & 10. & & 10.0 & & & & 17 & & & \\
\hline
\end{tabular}

Abbreviations: KNHANES Korea National Health and Nutrition Examination Survey, LDL-cholesterol Low density lipoprotein cholesterol, HDL-cholesterol high density lipoprotein cholesterol.

${ }^{1}$ Estimates shown as mean and standard error or \%.

${ }^{2}$ Defined using 2007 Korea growth chart, Normal weight (5th percentile $\leq \mathrm{BMI}<85$ th percentile); overweight $(85$ th percentile $\leq \mathrm{BMI}<95$ th percentile); obesity (BMI $\geq 95$ th percentile).

${ }^{3}$ P-trend $<0.05$ across weight status.

${ }^{4}$ Letters with different superscripts by weight status are significantly different at $\mathrm{P}<0.05$ by Tukey's multiple range test.

${ }^{5} \mathrm{P}<0.05$ for between group comparisons.

${ }^{6} \mathrm{P}<0.05$ for between group comparisons using $\mathrm{x}^{2}$ tests

${ }^{7}$ Atherogenic index $=\log$ (triglyceride/HDL-cholesterol).

${ }^{8}$ Definitions of metabolic co-morbidities are provided in Methods.

${ }^{9}$ Among elevated waist circumference, elevated triglycerides, reduced HDL cholesterol, elevated blood pressure, elevated fasting plasma glucose based on the 2007 pediatric IDF definition. 


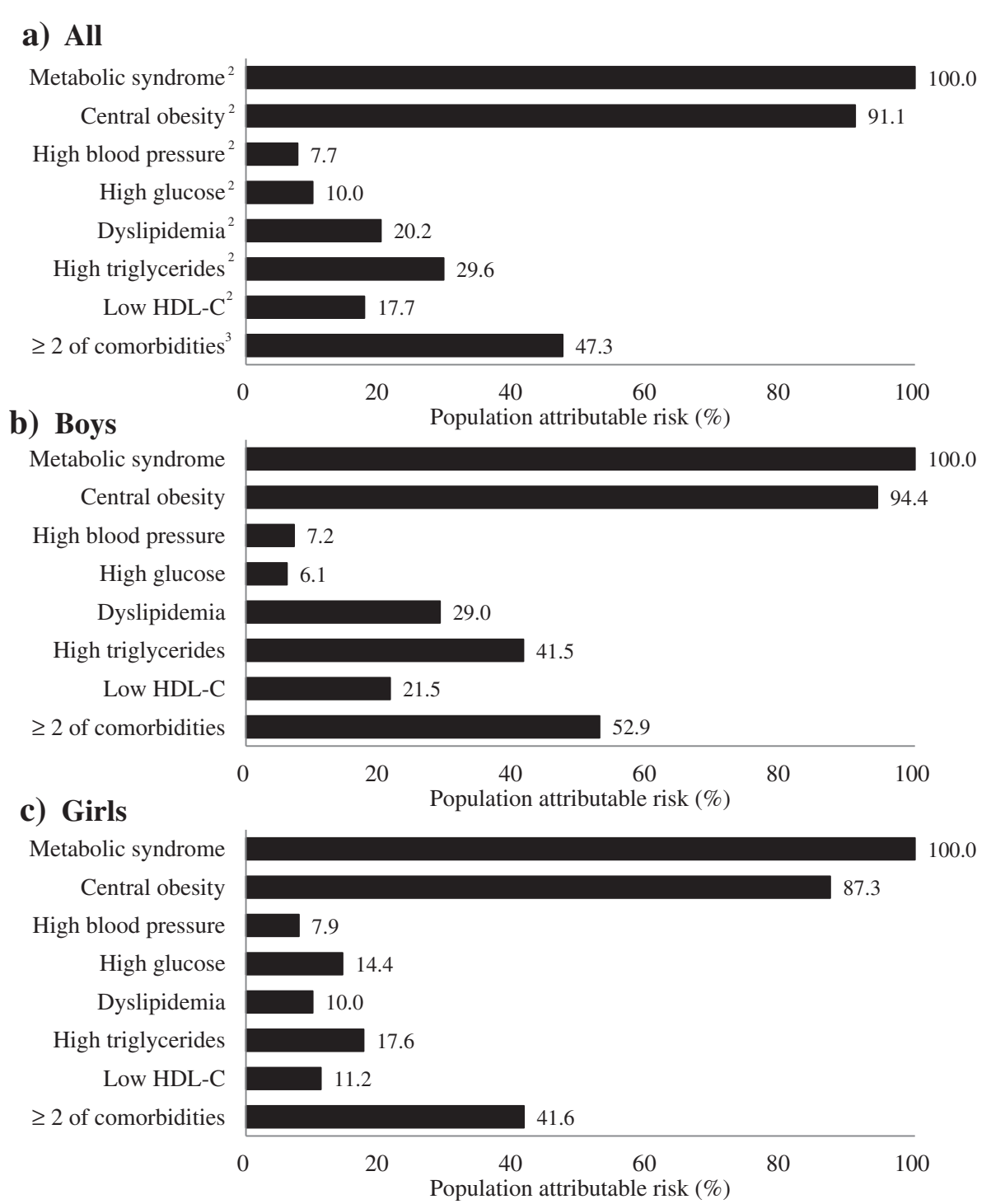

Figure 1 Risk of metabolic comorbidities attributable to overweight and obesity among children aged 10-19-y-old in South Korea: KNHANES 2007-2008. KNHANES, Korea National Health and Nutrition Examination Survey; HDL-C, high density lipoprotein cholesterol. ${ }^{1}$ Unadjusted population attributable risks estimated based on the method developed by Fleiss [15]. ${ }^{2}$ Definitions of metabolic co-morbidities are provided in Methods. ${ }^{3}$ Among elevated waist circumference, elevated triglycerides, reduced HDL cholesterol, elevated blood pressure, elevated fasting plasma glucose based on the 2007 pediatric IDF definition.

obese girls seemed to have a higher risk of high glucose (OR: 3.24; 95\% CI: 1.37-7.64) than girls with normal WC.

\section{Discussion}

We examined the association between weight status and metabolic co-morbidity among children by gender using the 2007-08 nationally representative data in South Korea. Obese, including centrally obese, children had a higher prevalence of metabolic co-morbidities than normalweight children. Overweight or obese children had also higher attributable risks of MetS, central obesity, and higher TG. Our results showed strong associations between weight status and metabolic outcomes for boys, in particular. Hyperglycemia was a significantly higher risk outcome among centrally obese girls only. Our findings suggest that dyslipidemia, in particular high TG, was a key co-morbidity, which is affected by increased body weight.

Overall prevalence of MetS in our participants (1.9\%) was similar to a previous study based on the 2005 KNHANES (1.8\%) [18]. Korean adolescents had a slightly higher MetS prevalence based on the IDF criteria than adolescents from some other Asian countries (e.g., 1.2\% in Hong Kong Chinese [19], 1.5\% in Asian Indian adolescents [20]), but a lower rate than US adolescents (5.5\%) [21] and Finland adolescents (2.4\%) [22]. 
Table 2 Associations (OR and 95\% Cl) between overweight and obesity and individual metabolic comorbidities among children aged 10-19-y-old in South Korea: KNHANES 2007-2008 ${ }^{1,2}$

\begin{tabular}{|c|c|c|c|c|c|c|c|c|}
\hline & $\begin{array}{l}\text { Model } 1 \\
\text { High blood pressure }^{3}\end{array}$ & $\begin{array}{l}\text { Model } 2 \\
\text { High glucose }^{4}\end{array}$ & $\begin{array}{l}\text { Model } 3 \\
\text { Dyslipidemia }^{5}\end{array}$ & $\begin{array}{l}\text { Model } 4 \\
\text { High triglyceride }\end{array}$ & $\begin{array}{l}\text { Model } 5 \\
\text { High cholesterol }^{5}\end{array}$ & $\begin{array}{l}\text { Model } 6 \\
\text { High LDL-C }\end{array}$ & $\begin{array}{l}\text { Model } 7 \\
\text { Low HDL-C }\end{array}$ & $\begin{array}{l}\text { Model } 8 \\
\geq 2 \text { of MetS components }{ }^{6}\end{array}$ \\
\hline \multicolumn{9}{|l|}{ In boys and girls } \\
\hline Overweight $^{7}$ & $1.46(0.94-2.28)$ & $1.27(0.64-2.51)$ & $3.36(2.35-4.81)$ & $3.80(2.29-6.30)$ & $2.33(1.27-4.30)$ & $1.91(0.98-3.74)$ & $2.17(1.14-4.11)$ & $3.83(2.25-6.52)$ \\
\hline Obese $^{7}$ & $1.90(1.05-3.45)$ & $1.54(0.68-3.47)$ & $6.21(3.59-10.75)$ & $6.87(4.05-11.64)$ & $2.80(1.10-5.62)$ & $3.81(1.87-7.80)$ & $4.46(2.23-8.89)$ & $26.97(14.95-48.65)$ \\
\hline Central obesity $^{8}$ & $1.15(0.69-1.90)$ & $1.65(0.82-3.35)$ & $3.87(2.45-6.13)$ & $4.12(2.67-6.37)$ & $2.04(1.07-3.90)$ & $3.01(1.58-5.74)$ & 3.78 (1.81-7.90) & $19.90(12.09-32.76)$ \\
\hline \multicolumn{9}{|l|}{ In boys } \\
\hline Overweight $^{7}$ & $1.31(0.78-2.21)$ & $1.21(0.49-2.99)$ & $5.00(3.07-8.13)$ & $6.28(3.11-12.7)$ & $2.91(1.30-6.49)$ & $2.65(1.16-6.03)$ & $2.64(1.25-5.57)$ & $5.31(2.52-11.18)$ \\
\hline Obese $^{7}$ & $2.32(1.08-4.98)$ & $1.18(0.31-4.45)$ & $10.10(4.84-21.07)$ & $11.50(5.24-25.02)$ & 5.17 (1.78-14.95) & $6.50(2.66-15.91)$ & $5.49(2.42-12.42)$ & $36.30(16.93-77.84)$ \\
\hline Central obesity $^{8}$ & $1.42(0.75-2.68)$ & $1.04(0.32-3.34)$ & $5.32(3.02-9.37)$ & $5.35(2.83-10.10)$ & 3.65 (1.59-8.35) & $5.80(2.66-12.67)$ & $3.65(1.65-8.07)$ & $23.59(12.16-45.76)$ \\
\hline \multicolumn{9}{|l|}{ In girls } \\
\hline Overweight ${ }^{7}$ & $1.55(0.70-3.43)$ & $0.83(0.28-2.51)$ & $1.93(1.05-3.53)$ & $1.95(0.86-4.41)$ & $2.05(0.72-5.90)$ & $1.68(0.48-5.92)$ & $1.66(0.55-5.05)$ & $2.69(1.18-6.14)$ \\
\hline Obese $^{7}$ & $0.99(0.31-3.17)$ & $1.71(0.57-5.09)$ & $2.37(1.20-4.71)$ & $3.04(1.38-6.71)$ & $0.75(0.15-3.85)$ & $1.30(0.34-4.97)$ & $1.64(0.50-5.36)$ & $13.84(6.45-29.70)$ \\
\hline Central obesity $^{8}$ & $0.64(0.24-1.69)$ & $3.24(1.37-7.64)$ & $2.13(1.14-3.95)$ & $2.87(1.39-5.91)$ & $0.77(0.21-2.88)$ & $1.10(0.36-3.38)$ & $2.66(0.94-7.55)$ & $16.79(8.51-33.11)$ \\
\hline
\end{tabular}

Abbreviations: KNHANES Korean National Health and Nutrition Examination Survey, OR odds ratio, Cl confidence interval.

${ }^{1}$ Each logistic regression model adjusted for age, gender, income, and urban-rural residence; among girls, further controlled for menarche status.

${ }^{2}$ Normal weight (5th percentile $\leq \mathrm{BMI}<85$ th percentile) group was the reference group in each model.

${ }^{3}$ Systolic blood pressure/diastolic blood pressure $\geq 90$ th percentiles of 2007 Korean CDC growth chart.

${ }^{4}$ Fasting blood glucose $\geq 100 \mathrm{mg} / \mathrm{dL}$.

${ }^{5}$ Triglyceride $>150 \mathrm{mg} / \mathrm{dL}$ or Total cholesterol $>200 \mathrm{mg} / \mathrm{dL}$ or LDL-cholesterol: $>130 \mathrm{mg} / \mathrm{dL}$ or HDL-cholesterol: $<35 \mathrm{mg} / \mathrm{dL}$.

${ }^{6}$ Among elevated waist circumference, elevated triglycerides, reduced HDL cholesterol, elevated blood pressure, elevated fasting plasma glucose based on the 2007 pediatric IDF definition

${ }^{7}$ By BMI percentile of 2007 Korea growth chart, overweight (85th percentile $\leq$ BMI $<95$ th percentile); obesity (BMI $>95$ th percentile).

${ }^{8}$ Waist circumference $\geq 90$ th percentile for age and gender based on 2007 Korean CDC growth chart. 
Among overweight and obese children, the MetS prevalence was higher than the previous 2005 KNHANES results (among overweight: $3.2 \%$ in $2007-08$ vs. $1.5 \%$, among obese: $24.7 \%$ vs. $14.7 \%$ ) [18]. This is likely due to their higher adiposity among the overweight and obese children over time. The MetS rate in obese South Korean children was higher than in those from other populations of children and adolescents, e.g., 19.4\% among Norwegians [23] and $10.3 \%$ among obese Chinese [24]. However, it should be noted that these studies focused on slightly different age ranges and used different MetS diagnosis criteria.

Obese children had a higher prevalence of most metabolic co-morbidities than non-obese children. These findings were consistent with the data reported for several other populations such as Mexican [25], Iranian [26], US [27], German [28], and Chinese [29] children. For example, risk of MetS was 16 times higher in US overweight adolescents compared to those with normal weight $\left(\mathrm{BMI}<85^{\text {th }}\right.$ percentile) $(14.5 \%$ vs. $0.9 \%)$ [27]. In a study from China, a slightly increasing trend of metabolic parameter levels was found at the $75^{\text {th }}$ percentile of BMI and a significant increase was found when $\mathrm{BMI} \geq 85^{\text {th }}$ percentile [29].

Interestingly, in our subjects, the overall prevalence of elevated BP (prehypertension and hypertension) was $17.5 \%$ and $21.2 \%$ of dyslipidemia, higher than other Asian populations [30-33]. According to a school-based population study of 88,974 Chinese adolescents, the prevalence was $10.3 \%$ [30]. Prehypertension can be predictive of future hypertension [34]. Our findings are consistent with the observation that pediatric hypertension is increasing with the rising pediatric obesity epidemic [35]. In South Korea, unlike for adults, blood pressure measurement is not a component of regular health examinations for children, thus, future monitoring and prevention efforts are needed to address this high prevalence. In terms of dyslipidemia, the prevalences were $11.1 \%$ in Chinese [32] and about $11.9 \%$ in Thai children [33], although differences exist on the definition of dyslipidemia. Most studies regarding dyslipidemia indicated that overweight and obese children were more likely to have dyslipidemia [36,37]. However, there are no local, official criteria of dyslipidemia for Korean children.

Boys had higher metabolic outcomes such as BMI, WC, BP levels and waist-to-height ratios; whereas, girls had higher TC and HDL levels. These gender differences were consistent with previous findings in other studies among adolescents in China [32] and even young adults aged 15-39 years among Asian Indians [38]. Likewise, boys may be the more vulnerable than girls to the risks of childhood metabolic disorders. Studying the reasons for boys' higher risks could shed some light on why the metabolic disorders are generally on the rise. Based on the same KNHANES 2007-08 data, South Korean men aged 20-65 years suffered worse metabolic outcomes than women (all $\mathrm{P}<0.05$ ), e.g., MetS: $15.8 \%$ in men vs. $11.6 \%$ in women, and had a higher average number of metabolic disturbances [39].

In addition, our results suggest a stronger association between childhood obesity and high TG (OR $=5.3$ in 1998 KNHANES [6] in vs. 6.9 in 2007-08 KNHANES, compared to children of normal weight). With few exceptions, the associations between overweight (including obese and centrally obese) and individual metabolic comorbidities were stronger in boys than in girls. Boys are therefore a more vulnerable group regarding metabolic outcomes, which may then lead to high risk of heart disease and other chronic diseases in adulthood. Additionally, Korean boys underestimated their weight [40]; therefore, we should help them to achieve a healthy body weight.

Previous research has suggested that obese children tend to have a higher risk of hyperglycemia and impaired fasting glucose [41]. However, our estimates do not show a difference in fasting blood glucose level and proportion of high glucose by weight status. Although a previous Korean study suggested that hyperglycemia is the most common individual component of the MetS in Korean adolescents (approximately 30\% in both 1998 and 2001) [18], we did not find the same trend. Further studies need to verify this discrepancy. Nevertheless, we found that centrally obese girls tend to have 3 times higher risk of having elevated blood glucose compared to non-centrally obese girls. Similar findings were reported in studies about adult women in Sweden [42] and China [43].

In the present study, overweight or obese children had high attributable risks of MetS and central obesity. High TG (around 30\% attributable risk) follows, which confers the highest risk of individual co-morbidities. While there is no or a very low prevalence of metabolic co-morbidities among normal-weight children, obese children had a high prevalence of MetS and central obesity. At present, overall, Korean children have little understanding of MetS, central obesity, or dyslipidemia. The importance of related health education was undervalued. Therefore, education programs to improve children's recognition of these health dangers and their possible outcomes are needed.

This study has several key strengths. First, it was based on a recent, nationally representative sample in South Korea, and our analysis took into account the complex sampling design effect to provide representative estimates. Moreover, we investigated several metabolic comorbidities of overweight or obesity among children.

On the other hand, our study could not employ longitudinal models due to data limitations which preclude causal inference and the estimates may suffer from problems such as reverse causation. Then, we categorized 
several variables of anthropometric and biochemical measurements. Categorization is a common practice in biomedical research, which facilitates the interpretation of model parameters and provides meaningful estimates with important clinic and public health implications. This is in line with the aims and scope of this study. However, the limitations of categorization should also be noted because the information in the data is not fully utilized. Future research that examines relevant variables on a continuous scale is warranted and could potentially help provide more insight. In addition, subjects were excluded in the analysis if weight or metabolic comorbidities were not measured, which limited our sample size and could potentially introduce selection bias. However, we explored the possibility of potential selection bias and our analysis did not suggest significant difference between the study sample and the whole sample. Moreover, the KHANES is the only available data set that can be used to examine the levels of biochemical indicators and estimate the prevalence patterns of chronic conditions at a national level. However, despite of the limitations, such as missing values, existing studies indicate that KNHANES can still provide valid and reasonably representative estimates, e.g. the prevalence of metabolic disorders among children $[6,18,21]$.

\section{Conclusions}

Childhood obesity is becoming a serious public health problem in South Korea, as $19.0 \%$ of children were overweight or obese, and $8.1 \%$ had central obesity. The prevalence of elevated BP (17.5\%) and dyslipidemia (21.2\%) was high among children in South Korea. In addition, most of the obese children (91.1\%) had at least one metabolic co-morbidity. MetS and dyslipidemia, especially high TG, were the key co-morbidities among obese children. Lipid profiles of South Korean children are affected by their weight status. Intervention programs are needed to prevent and control obesity and its co-morbidities, in particular targeting at obesity in children.

\section{Abbreviations \\ BMI: Body mass index; BP: Blood pressure; HDL-C: High-density lipoprotein cholesterol; IDF: International Diabetes Federation; KNHANES: The Korea National Health and Nutrition Examination Surveys; LDL-C: Low-density lipoprotein cholesterol; MetS: Metabolic syndrome; PAR: Population attributable risk; TC: Total cholesterol; TG: Triglyceride.}

\section{Competing interests}

The authors declare that they have no competing interests.

\section{Authors' contributions}

HL and YW had full access to the data in the study and take full responsibility for the integrity of the study. $\mathrm{HL}$ analyzed the data. $\mathrm{HL}$ and YW drafted the paper. HX revised the manuscript. Findings were jointly interpreted by all authors. All authors contributed to successive drafts. The authors read and approved the final manuscript.

\section{Acknowledgement}

The study was supported in part by research grants from the National Institute of Diabetes and Digestive and Kidney Diseases (R01DK81335-01A1) and the National Institute of Child Health and Human Development (1R01HD064685-01A1, U54 HD070725). The content is solely the responsibility of the authors and does not necessarily represent the official views of the National Institutes of Health.

\section{Author details}

${ }^{1}$ Department of Medical Nutrition, Graduate School of East-West Medical Science, Kyung Hee University, Yongin-si, Gyeonggi-do, Republic of Korea. ${ }^{2}$ Research Institute of Medical Nutrition, Kyung Hee University, Seoul, Republic of Korea. ${ }^{3}$ Johns Hopkins Global Center on Childhood Obesity, Department of International Health, Johns Hopkins Bloomberg School of Public Health, Baltimore, MD, USA. ${ }^{4}$ Department of Epidemiology and Environmental Health, School of Public Health and Health Professions, University at Buffalo, State University of New York, Buffalo, NY, USA.

Received: 6 May 2013 Accepted: 17 February 2014

Published: 25 March 2014

\section{References}

1. Wang Y, Lobstein T: Worldwide trends in childhood overweight and obesity. Int J Pediatr Obes 2006, 1(1):11-25.

2. Bradford NF: Overweight and obesity in children and adolescents. Prim Care 2009, 36(2):319-339.

3. Dietz WH, Robinson TN: Clinical practice, overweight children and adolescents. N Engl J Med 2005, 352(20):2100-2109.

4. Korean Centers for Disease Control and Prevention: National health statistics in 2011 based on the Fifth Korea National Health and Nutrition Examination Survey (KNHANES V), 2011. In. Seoul: Korean Centers for Disease Control and Prevention; 2012.

5. Korean Centers for Disease Control and Prevention: National health statistics in 2008 based on the Fourth Korea National Health and Nutrition Examination Survey (KNHANES IV), 2008. In. Seoul: Korean Centers for Disease Control and Prevention; 2010.

6. Kim HM, Park J, Kim HS, Kim DH, Park SH: Obesity and cardiovascular risk factors in Korean children and adolescents aged 10-18 years from the Korean National Health and Nutrition Examination Survey, 1998 and 2001. Am J Epidemiol 2006, 164(8):787-793.

7. Lim H, Wang Y: Body weight misperception patterns and their association with health-related factors among adolescents in South Korea. Obesity 2013, 21(12):2596-2603.

8. The Ministry of Health, Welfare, and Family Affairs \& Center for Disease Control and Prevention: The guideline for the usage of KNHANES raw data. Seoul: Korean Centers for Disease Control and Prevention; 2007.

9. Korean Centers for Disease Control and Prevention: The Fourth Korea National Health and Nutrition Examination Survey (KNHANES IV), 2007-2009. Seoul: Korean Centers for Disease Control and Prevention; 2010.

10. Friedewald WT, Levy RI, Fredrickson DS: Estimation of the concentration of low-density lipoprotein cholesterol in plasma, without use of the preparative ultracentrifuge. Clin Chem 1972, 18(6):499-502.

11. Moon JS, Lee SY, Nam CM, Choi JM, Choe BK, Seo JW, Oh K, Jang MJ, Hwang SS, Yoo MH, Kim YT, Lee CG: Korean national growth charts: review of developmental process and an outlook. Korean J Pediatr 2007, 2008(51):1-25.

12. Lee SY, Park HS, Kim DJ, Han JH, Kim SM, Cho GJ, Kim DY, Kwon HS, Kim SR, Lee CB, Oh SJ, Park CY, Yoo HJ: Appropriate waist circumference cutoff points for central obesity in Korean adults. Diabetes Res Clin Pract 2007, 75(1):72-80.

13. NHBPEP: The fourth report on the diagnosis, evaluation, and treatment of high blood pressure in children and adolescents. Pediatrics 2004, 114(2 Suppl 4th Report):555-576.

14. American Diabetes Association: Diagnosis and classification of diabetes mellitus. Diabetes Care 2011, 34(Suppl 1):S62-69.

15. Kavey RE, Daniels SR, Lauer RM, Atkins DL, Hayman LL, Taubert K: American Heart Association guidelines for primary prevention of atherosclerotic cardiovascular disease beginning in childhood. Circulation 2003, 107(11):1562-1566. 
16. Zimmet P, Alberti G, Kaufman F, Tajima N, Silink M, Arslanian S, Wong G, Bennett $P$, Shaw J, Caprio S: The metabolic syndrome in children and adolescents. Lancet 2007, 369(9579):2059-2061.

17. Fleiss $\mathrm{L}$ : Inference about population attributable risk from crosssectional studies. Am J Epidemio/ 1979, 110(2):103-104.

18. Park MJ, Boston BA, Oh M, Jee SH: Prevalence and trends of metabolic syndrome among Korean adolescents: from the Korean NHANES survey, 1998-2005. J Pediatr 2009, 155(4):529-534.

19. Kong AP, Ko GT, Ozaki R, Wong GW, Tong PC, Chan JC: Metabolic syndrome by the new IDF criteria in Hong Kong Chinese adolescents and its prediction by using body mass index. Acta Paediatr 2008 97(12):1738-1742.

20. Vikram NK, Misra A, Pandey RM, Luthra K, Bhatt SP: Distribution and cutoff points of fasting insulin in Asian Indian adolescents and their association with metabolic syndrome. J Assoc Physicians India 2008, 56:949-954.

21. Park J, Hilmers DC, Mendoza JA, Stuff JE, Liu Y, Nicklas TA: Prevalence of metabolic syndrome and obesity in adolescents aged 12 to 19 years: comparison between the United States and Korea. J Korean Med Sci 2010, 25(1):75-82.

22. Pirkola J, Tammelin T, Bloigu A, Pouta A, Laitinen J, Ruokonen A, Tapanainen P, Jarvelin MR, Vaarasmaki M: Prevalence of metabolic syndrome at age 16 using the international diabetes federation paediatric definition. Arch Dis Child 2008, 93(11):945-951.

23. Kolsgaard ML, Andersen LF, Tonstad S, Brunborg C, Wangensteen T, Joner G: Ethnic differences in metabolic syndrome among overweight and obese children and adolescents: the Oslo Adiposity Intervention Study. Acta Paediatr 2008, 97(11):1557-1563.

24. Fu JF, Liang L, Zou CC, Hong F, Wang CL, Wang XM, Zhao ZY: Prevalence of the metabolic syndrome in Zhejiang Chinese obese children and adolescents and the effect of metformin combined with lifestyle intervention. Int J Obes (Lond) 2007, 31(1):15-22.

25. Perichart-Perera O, Balas-Nakash M, Schiffman-Selechnik E, Barbato-Dosal A Vadillo-Ortega F: Obesity increases metabolic syndrome risk factors in school-aged children from an urban school in Mexico city. J Am Diet Assoc 2007, 107(1):81-91.

26. Hamidi A, Fakhrzadeh H, Moayyeri A, Pourebrahim R, Heshmat R, Noori M, Rezaeikhah Y, Larijani B: Obesity and associated cardiovascular risk factors in Iranian children: a cross-sectional study. Pediatr Int 2006, 48(6):566-571.

27. Pan $Y$, Pratt CA: Metabolic syndrome and its association with diet and physical activity in US adolescents. J Am Diet Assoc 2008, 108(2):276-286. discussion 286.

28. Reinehr T, Andler W, Denzer C, Siegried W, Mayer H, Wabitsch M: Cardiovascular risk factors in overweight German children and adolescents: relation to gender, age and degree of overweight. Nutr Metab Cardiovasc Dis 2005, 15(3):181-187.

29. Ma GS, Li YP, Hu XQ, Cui ZH, Yang XG, Chen CM: Report on childhood obesity in China (2). Verification of BMI classification reference for overweight and obesity in Chinese children and adolescents. Biomed Environ Sci 2006, 19(1):1-7.

30. Cao ZQ, Zhu L, Zhang T, Wu L, Wang Y: Blood pressure and obesity among adolescents: a school-based population study in china. Am J Hypertens 2012, 25(5):576-582.

31. Redwine KM, Acosta AA, Poffenbarger T, Portman RJ, Samuels J: Development of hypertension in adolescents with pre-hypertension. J Pediatr 2012, 160(1):98-103.

32. Liao Y, Liu Y, Mi J, Tang C, Du J: Risk factors for dyslipidemia in Chinese children. Acta Paediatr 2008, 97(10):1449-1453.

33. Rerksuppaphol S, Rerksuppaphol L: Prevalence of dyslipidemia in Thai schoolchildren. J Med Assoc Thai 2011, 94(6):710-715.

34. Falkner B, Gidding SS, Portman R, Rosner B: Blood pressure variability and classification of prehypertension and hypertension in adolescence. Pediatrics 2008, 122(2):238-242.

35. Hansen ML, Gunn PW, Kaelber DC: Underdiagnosis of hypertension in children and adolescents. JAMA 2007, 298(8):874-879.

36. Boyd GS, Koenigsberg J, Falkner B, Gidding S, Hassink S: Effect of obesity and high blood pressure on plasma lipid levels in children and adolescents. Pediatrics 2005, 116(2):442-446.

37. I'Allemand-Jander D: Clinical diagnosis of metabolic and cardiovascular risks in overweight children: early development of chronic diseases in the obese child. Int J Obes (Lond) 2010, 34(Suppl 2):S32-S36.
38. Gupta R, Misra A, Vikram NK, Kondal D, Gupta SS, Agrawal A, Pandey RM: Younger age of escalation of cardiovascular risk factors in Asian Indian subjects. BMC Cardiovasc Disord 2009, 9:28.

39. Lim H, Nguyen T, Choue R, Wang Y: Sociodemographic disparities in the composition of metabolic syndrome components among adults in South Korea. Diabetes Care 2012, 35(10):2028-2035.

40. Lee G, Ha Y, Vann JJ, Choi E: Weight perception and dieting behavior among Korean adolescents. J Sch Nurs 2009, 25(6):427-435.

41. De Ferranti SD, Osganian SK: Epidemiology of paediatric metabolic syndrome and type 2 diabetes mellitus. Diab Vasc Dis Res 2007, 4(4):285-296.

42. Lewitt MS, Hilding A, Brismar K, Efendic S, Ostenson CG, Hall K: IGF-binding protein 1 and abdominal obesity in the development of type 2 diabetes in women. Eur J Endocrinol 2010, 163(2):233-242.

43. He Y, Zhai F, Ma G, Feskens EJ, Zhang J, Fu P, Van't Veer P, Yang X: Abdominal obesity and the prevalence of diabetes and intermediate hyperglycaemia in Chinese adults. Public Health Nutr 2009, 12(8):1078-1084

doi:10.1186/1471-2458-14-279

Cite this article as: Lim et al:: Association between obesity and metabolic co-morbidities among children and adolescents in South Korea based on national data. BMC Public Health 2014 14:279.

\section{Submit your next manuscript to BioMed Central and take full advantage of:}

- Convenient online submission

- Thorough peer review

- No space constraints or color figure charges

- Immediate publication on acceptance

- Inclusion in PubMed, CAS, Scopus and Google Scholar

- Research which is freely available for redistribution 